\title{
Duas espécies novas de Anthurium Schott (ARaceae) PARA O BRASIL
}

\author{
Marcus A. Nadruz Coelho ${ }^{1} \&$ Eduardo Luís Martins Catharino ${ }^{2}$
}

\begin{abstract}
Resumo
(Duas espécies novas de Anthurium Schott (Araceae) para o Brasil) Duas espécies novas do gênero Anthurium são descritas para a Serra da Bocaina, estado de São Paulo, ambas até o momento endêmicas dessa localidade. Anthurium bocainensis pertence à seção Urospadix, subseção Flavescentiviridia e A. ameliae pertence à seção Urospadix subseção Obscureviridia, e ocorrem no bioma floresta atlântica. São fornecidas diagnoses, ilustrações e comentários à cerca da distribuição geográfica, ecologia, registro de floração, frutificação e conservação para cada espécie.
\end{abstract}

Palavras-chave: Araceae, Anthurium, taxonomia, Brasil.

\section{Abstract}

(Two new species of Anthurium Schott (Araceae) from Brazil) Two new species of the genus Anthurium are described from the Serra da Bocaina, São Paulo state, Brazil. Both currently endemic to this area and thus considered part of the Atlantic Forest biome. Anthurium bocainensis belongs to sect. Urospadix, subsect. Flavescentiviridia, and A. ameliae belongs to sect. Urospadix subsect. Obscureviridia. Diagnoses, descriptions, illustrations and commentary on geographical distribution, ecology, flowering and fruiting times and conservation status are provided for each species.

Key-words: Araceae, Anthurium, taxonomy, Brazil.

\section{INTRODUÇÃO}

A Serra da Bocaina está localizada entre os estados do Rio de Janeiro e São Paulo e pertence ao complexo da Serra do Mar, possuindo porções elevadas em altiplanos com altitudes superiores a $2.000 \mathrm{~m}$ a.n.m. onde as florestas tropicais de encosta diluem-se em florestas temperadas com araucárias e Podocarpus, formações herbáceo-arbustivas e campos de altitude (IBAMA 2004). Espécies do gênero Anthurium ocorrem tanto nas florestas contínuas às da encosta como nas formações florestais "insulares" nas porções mais elevadas, bem como no interior de densas formações arbustivas de altitude. As duas espécies aqui descritas pertencem às formações florestais das porções elevadas da serra. A. bocainensis ocorre preferencialmente nas formações arbóreas baixas das porções em geral acima de $1.500 \mathrm{~m}$ de altitude, sobre a serrapilheira, enquanto o A. ameliae ocorre nas florestas ripárias, normalmente sobre solos litólicos próximos a cursos d'água que correm para o mar, despencando nas escarpas litorâneas.

O gênero neotropical Anthurium Schott situa-se na subfamília Pothoideae, tribo Potheae, com aproximadamente 1.000 espécies (Keating 2002), distribuídas do norte do México e das Grandes Antilhas ao sul do Brasil e norte da Argentina e Uruguai, nas baixas e médias elevações, com alcance de maior diversidade no Panamá, Colômbia e Equador (Mayo et al. 1997, Carroll 2003). No Brasil ocorre em todas as regiões, com cerca de 120 espécies de acordo com o checklist de Mayo et al. (1996).

Atualmente o gênero Anthurium está subdividido em 19 seções (Croat 1983, Keating 2002). As subseções Flavescentiviridia e Obscureviridia pertencem a seção Urospadix, que foi descrita por Engler (1878). As espécies desta seção estão concentradas no Brasil leste e sudeste (Coelho 2004).

\footnotetext{
Artigo recebido em 06/2005. Aceito para publicação em 09/2005.

${ }^{1}$ Pesquisador Titular III, Instituto de Pesquisas Jardim Botânico do Rio de Janeiro, Rua Pacheco Leão 915, 22460-030, Jardim Botânico, Rio de Janeiro, RJ, Brasil. mnadruz@jbrj.gov.br

${ }^{2}$ Pesquisador Científico IV, Instituto de Botânica de São Paulo, Av. Miguel Stefano, São Paulo, SP, Brasil. mcatarin@uol.com.br
} 
Anthurium bocainensis Catharino \& Nadruz sp. nov. Tipo: Brasil. São Paulo. São José do Barreiro, Serra da Bocaina, Parque Nacional da Bocaina. Mata de altitude no divisor de águas do Rio Mambucaba e Rio dos Veados. 20.VII.1994, fl., L. Rossi \& E. L. M. Catharino 1603 (Holótipo - SP, Isótipo - RB). Fig. 1 a-h

Anthurium bocainensis, sp. nov., Anthurium lhotzkyano Schott affine, sed foliorum lamina lanceolato-ovata, in pagina abaxiali leviter pruinosa, spatha naviculari, spadicis stipite $1.2 \mathrm{~cm}$ longo (in Anthurium lhotzkyano: foliorum lamina ovata, non pruinosa, spatha plana, patens, spadicis stipes brevissimus).

Terrestre, caule ereto; entrenós $0,4-1 \mathrm{~cm}$ compr.; mesófilos silépticos inteiros a decompostos no ápice, decompostos e caducos para a base do caule, 1,9-3,2 cm compr.; profilos silépticos inteiros a decompostos no ápice, decompostos e caducos para a base do caule; bainha peciolar vinácea em pecíolo jovem, tornando-se esverdeada com margens amarelo-vináceas a cor de palha, 2-2,7 cm compr.; pecíolo foliar esverdeado, arredondado abaxialmente, achatado a levemente sulcado com margens obtusas adaxialmente, 20,2-52 cm compr.; genículo esverdeadoamarelado e mais grosso que o pecíolo, levemente sulcado adaxialmente, $0,5-3 \mathrm{~cm}$ compr.; lâmina foliar perpendicular, cartácea em material vivo, membranácea em material seco, esverdeada, levemente discolor, levemente pruinosa abaxialmente, oval-lanceolada, base cordada, lobos arredondados e sino triangular, ápice rostrado, curtamente apiculado, 14,3-33 × 3,7-14,5 cm na região mediana; nervura central arredondada abaxialmente, aguda adaxialmente; nervuras basais $3 \mathrm{em}$ ambos os lados, fortemente impressas adaxialmente, a mais externa unindo-se a margem ainda no lobo posterior, a mediana juntandose a margem no terço inferior e a mais interna unindo-se no terço superior; nervuras laterais primárias 4-10 em ambos os lados, sendo visíveis do meio para o ápice; nervuras laterais secundárias da metade inferior, unindo-se em tênue nervura coletora entre as nervuras central e coletora; nervura coletora saindo em ângulo agudo em relação a nervura central, tornando-se elíptica até o ápice da lâmina foliar, $0,7-2,4 \mathrm{~cm}$ afastada da margem na região mediana, unindo-se a margem a cerca de 1,5 cm do ápice; pedúnculo vináceo-acastanhado, esverdeado no ápice, roliço, 14-50 cm compr.; espata membranácea, esverdeada, esverdeado-vinácea com as margens levemente acastanhadas a vináceas, perpendicular em relação ao pedúnculo, linear-lanceolada, navicular, formando ângulo agudo com o pedúnculo, 2,5-7,2 ×0,5-1,1 cm, decorrência $0,2 \mathrm{~cm}$ compr.; espádice estipitado, acastanhado, cilíndrico, 2,5-8,8 cm compr., $0,3 \mathrm{~cm}$ grossura, estípite vináceo, 1-1,8 cm compr., quatro flores na espiral principal e seis na espiral secundária, tépalas amarronzadas com margens apicais rosadas, cuculadas, levemente rugosas, dorsalmente agudas e levemente convexas internamente nas tépalas laterais, fortemente convexas nas tépalas anteriores/ posteriores ventralmente, $0,1-0,15 \times 0,09-0,1$ $\mathrm{cm}$, androceu com estames opostos as tépalas anteriores/posteriores com filetes engrossados, convexos dorsalmente, estames opostos as tépalas laterais delgados, filetes com margens paralelas, anteras dorsifixas, $0,15-0,18 \times 0,06-$ $0,07 \mathrm{~cm}$, gineceu de estigma vináceo, globoso, ovário oblongo a levemente globoso, séssil, bilocular, 1 óvulo por lóculo envolto em mucilagem hialina pegajosa, placentação subapical, $0,11-0,15 \times 0,1-0,11 \mathrm{~cm}$; bagas imaturas esverdeadas.

Parátipo: BRASIL. SÃO PAULO: Bananal, 5.III.1977, G. Martinelli 1106 (RB). São José do Barreiro, 17.VII.1994, E. L. M. Catharino \& L. Rossi 1952 (SP); IV.2003, E. L. M. Catharino \& L. Rossi 2775 (SP).

Anthurium bocainensis é muito próximo de A. lhotzkyanum Schott, possuindo nervuras central e laterais primárias mais evidentes em ambas as faces e coloração verde mais clara - pálida - na face abaxial da lâmina foliar, caracterizando a subseção Flavescentiviridia. 


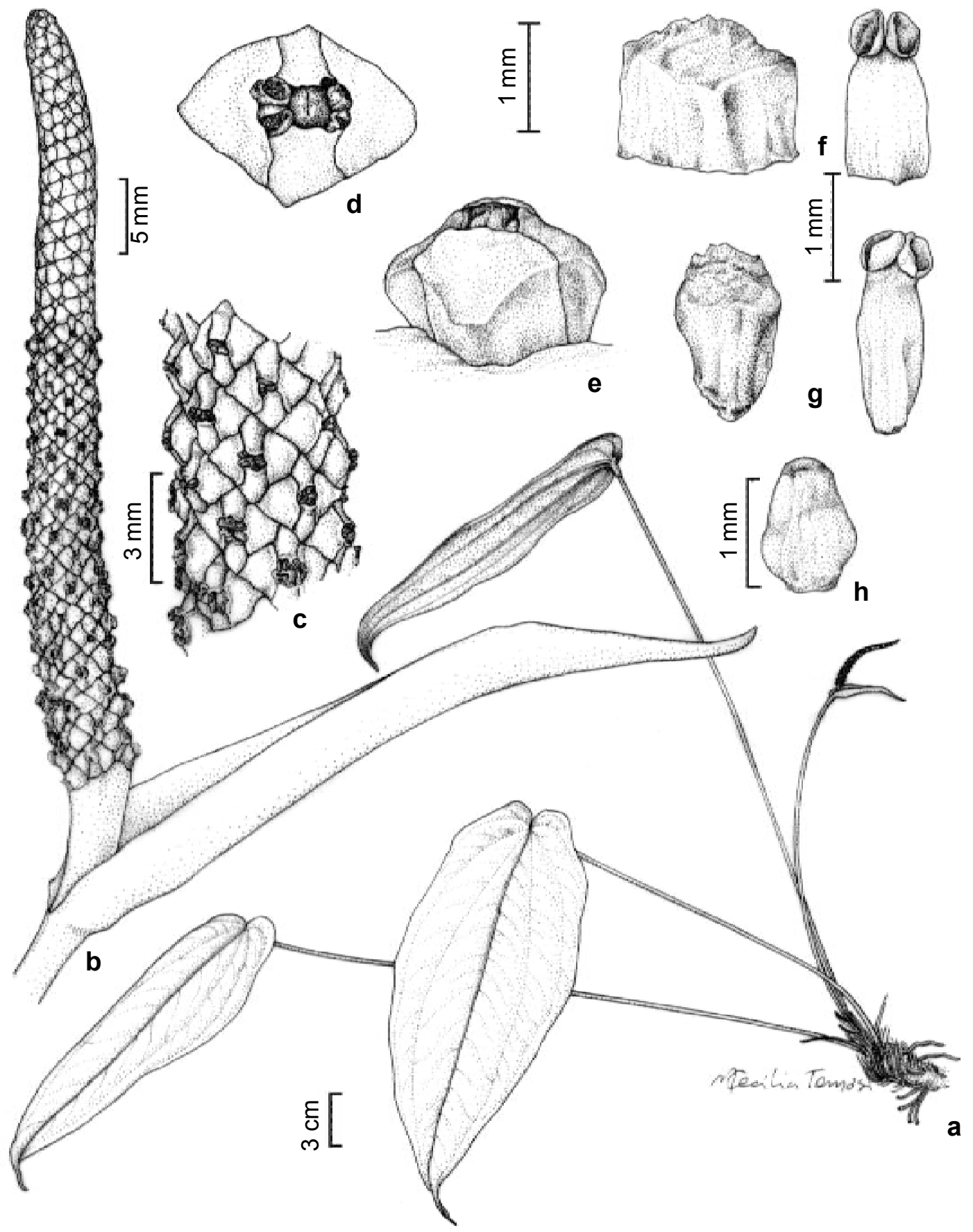

Figura 1 - Anthurium bocainensis Catharino \& Nadruz: a-hábito; b-espádice; c-detalhe do espádice; d-flor em vista frontal; e-flor em vista lateral; f-tépala e estame externos; g-tépala e estame internos; h-ovário (Catharino \& Rossi 2775). 
Difere ainda por apresentar lâmina foliar levemente pruinosa abaxialmente, ovallanceolada, três nervuras basais fortemente impressas na face adaxial, espata navicular, formando ângulo agudo com o pedúnculo, espádice com estípite 1,2 cm compr., contra lâmina foliar não pruinosa, ovada, nervuras basais duas, levemente impressas na face adaxial, espata plana e reta, formando ângulo reto com o pedúnculo e espádice curtamente estipitado (subséssil) em A. lhotzkyanum.

Espécie terrestre, ocorrendo em florestas baixas de altitude, sobre a serrapilheira em locais úmidos e ensolarados, tendo sido encontrado florescendo nos meses de março e julho. Pode ser reconhecida pelas características mencionadas acima, acrescentando lâmina foliar levemente deflexa com nervuras central e basais fortemente impressas adaxialmente.

Tem ocorrência restrita ao município de Bananal, nordeste do estado de São Paulo, dentro e no entorno do Parque Nacional da Bocaina, provavelmente também no município de São José do Barreiro e outros limítrofes. É necessário um estudo complementar de coletas e acompanhamento de material cultivado para observação completa do fruto maduro. $\mathrm{O}$ material cultivado se desenvolve com as mesmas características daquele encontrado na natureza.

Até o momento, seguindo os critérios da lista vermelha das espécies ameaçadas, $A$. bocainensis pode ser considerada em perigo critico (CR), por ocorrer numa área estimada menor que $100 \mathrm{~km}^{2}$ conhecida somente de uma única localidade (IUCN 2001).

O epíteto específico homenageia a localidade de ocorrência da espécie em questão, a Serra da Bocaina, considerada uma área de riqueza singular em relação a espécies de Araceae e outras regiões da fachada atlântica brasileira.
Anthurium ameliae Nadruz \& Catharino sp. nov. Tipo: Brasil. São Paulo. Bananal, Serra da Bocaina, alto vale do Rio Paca (Bracuhy), IV.2003, E. L. M. Catharino 2774 (Holótipo - SP, Isótipo - RB). Fig. 2 a-e

Anthurium ameliae sp. nov., Anthurium maximiliani Schott affine, sed foliorum lamina oblongo-lanceolata, lobo antico lobis posticis 11-17-plo longiore, sinu triangulari, nervis basalibus utrinque 2, nervis lateralibus primariis utrinque 12-25, in superficiebus ambabus folii leviter aut haud impressis, spatha recurvata (in Anthurium maximiliani: lobus anticus lobis posticis 5-plo longior, sinus obovatus, nervi basilares utrinque 3-4, nervi lateralis primarii utrinque 13-15, pagina adaxiali impressi, pagina abaxiali prominentes, spatha reflexa), differt.

Terrestre ou rupícola; caule ereto, subereto a rastejante; raízes grossas, ocres, esverdeadas quando molhadas, esbranquiçadas quando enterradas no substrato, saindo ao longo do caule, inclusive próximo às folhas, $0,5-$ $0,8 \mathrm{~cm}$ diâm.; entrenós curtos, $0,4-1 \mathrm{~cm}$ compr.; mesófilos silépticos esverdeados quando novos tornando-se cor de palha, triangulares, inteiros no ápice, inteiros a caducos para a base do caule, 10-17,3 $\times 5-$ $3,2 \mathrm{~cm}$ na base; prófilos silépticos esverdeados quando novos, tornando-se cor de palha, triangulares, inteiros no ápice, inteiros a caducos para a base do caule, $5,2-6,4 \mathrm{~cm}$ compr.; bainha peciolar 7-8 cm compr.; pecíolo foliar esverdeado, levemente sulcado com margens obtusas, raramente achatado a roliço para a base adaxialmente, arredondado abaxialmente, 33,3-55 cm compr., 0,7-0,8 cm espessura; genículo esverdeado discolor a esverdeado-amarelado, mais grosso em relação ao pecíolo, levemente canaliculado, $3-4 \mathrm{~cm}$ compr., $0,8-1 \mathrm{~cm}$ diâm.; lâmina foliar levemente cartácea em material vivo, membranácea em material seco, esverdeada, 


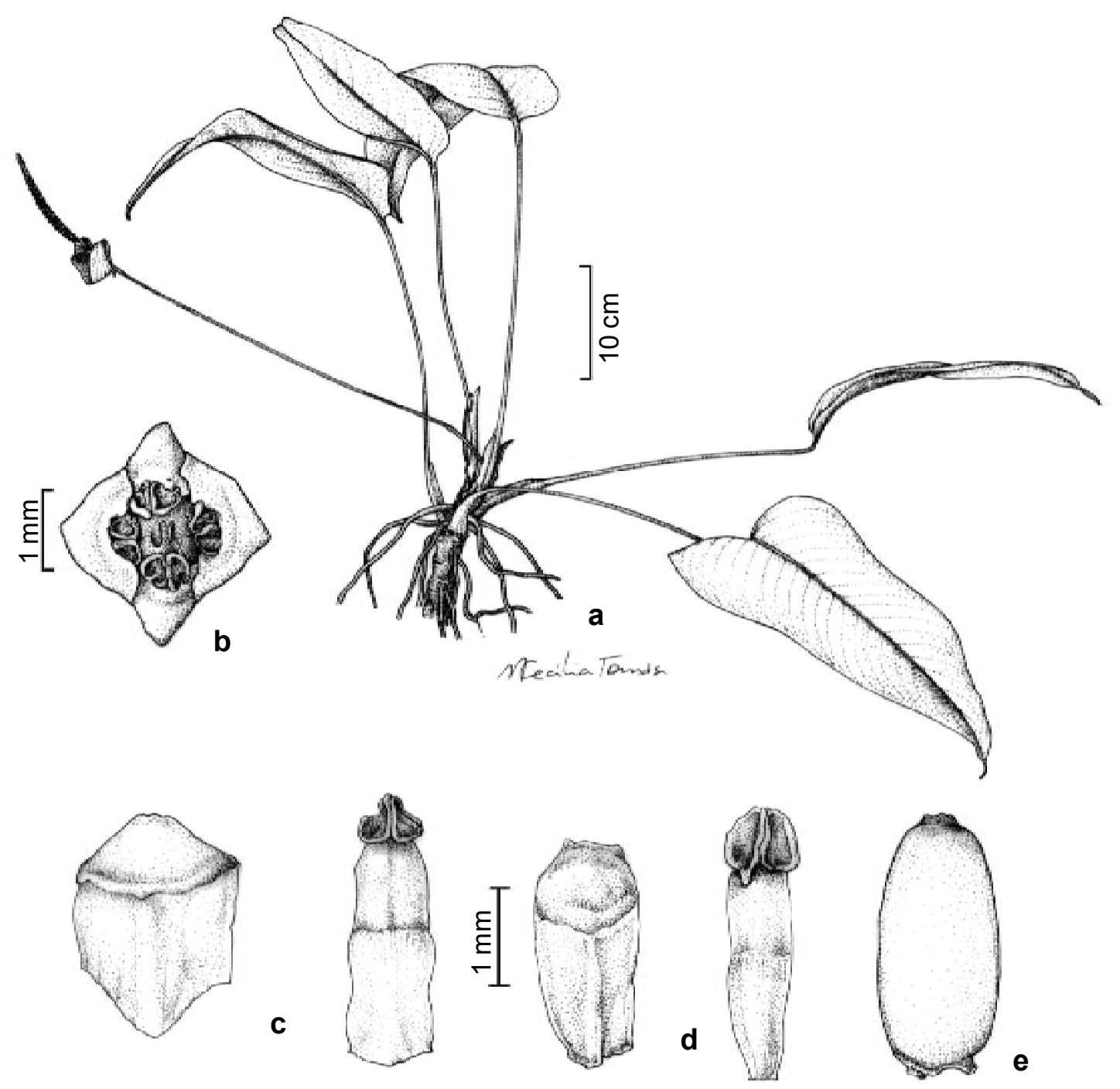

Figura 2 - Anthurium ameliae Nadruz \& Catharino: a. hábito; b. flor em vista frontal; c. tépala e estame externos; d. tépala e estame internos; e- ovário (Catharino 2776).

levemente discolor, perpendicular a sub-ereta em relação ao pecíolo, oblongo-lanceolada, de base truncada a geralmente cordada, lobos arredondados, sino triangular, ápice rostrado, $32-52 \times 15-19,9 \mathrm{~cm}$; nervura central, geralmente aguda a subaguda adaxialmente, arredondada abaxialmente; nervuras basais duas levemente impressas a somente visíveis na face adaxial, a mais externa terminando na margem da base dos lobos, a mais interna terminando na margem no quarto inferior; nervuras laterais primárias levemente impressas a somente visíveis na face adaxial, levemente proeminentes a somente visíveis na face abaxial, 12 a 25 de cada lado; nervura coletora $0,8-1,7 \mathrm{~cm}$ afastada da margem; pedúnculo esverdeado, roliço, 44-51,7 cm compr., $0,5 \mathrm{~cm}$ espessura; espata esverdeadovinácea a esverdeada com margens vináceas, membranácea, lanceolada, plana, curvada para trás, formando ângulo agudo com o pedúnculo, 9,5-11 × 1-4 cm, decorrência 1,3 cm compr.; espádice séssil, cilíndrico, amarronzado, 8,5$9,1 \mathrm{~cm}$ compr., seis a sete flores na espiral primária, nove flores na espiral secundária; flores com tépalas cuculadas, lisas ventral- 
mente e levemente rugosas dorsalmente, dorsalmente subcarenadas e levemente convexas ventralmente nas tépalas laterais e fortemente convexas ventralmente e subcarenadas dorsalmente nas tépalas anteriores/posteriores, $0,3-0,36 \times 0,25-0,27 \mathrm{~cm}$, androceu com estames opostos as tépalas anteriores/posteriores com filetes levemente côncavos dorsalmente, estames opostos as tépalas laterais delgados, filetes com margens paralelas, anteras dorsifixas, 0,3-0,38 ×0,17-0,19 cm, gineceu de estigma proeminente, ovário oblongo a levemente globoso, bilocular, um óvulo por lóculo envolto em mucilagem hialina pegajosa, placentação subapical, $0,27-0,39 \times 0,12-0,15$ cm; bagas não observadas.

Parátipo: BRASIL. SÃO PAULO: Bananal, IV.2003, E. L. M. Catharino 2776 (SP).

Anthurium ameliae está posicionada na subseção Obscureviridia por apresentar lâmina foliar esverdeada levemente discolor e nervuras laterais primárias pouco proeminentes ou somente visíveis. Pode ser confundida com A. maximiliani Schott, diferindo desta por apresentar lâmina foliar oblongo-lanceolada, proporção do tamanho dos lobos anterior e posterior $1 / 11$ a $1 / 17$, sino triangular, nervuras basais duas, nervuras laterais primárias 12-25, levemente impressas a somente visíveis na face adaxial, levemente proeminentes a somente visíveis na face abaxial, espata curvada para trás, contra proporção do tamanho dos lobos anterior e posterior $1 / 5$, sino obovado, nervuras basais 3-4, nervuras laterais primárias 13-15, impressas adaxialmente e proeminentes abaxialmente, espata reflexa em $A$. maximiliani.

Espécie terrestre, até o momento encontrada somente na serra da Bocaina, em uma única localidade no município de Bananal, São Paulo, em floresta de altitude voltada para a face atlântica, no vale do rio Bracuhy. É uma planta robusta para as congêneres, distinguida pela forma alongada e deflexa da lâmina foliar, pelas nervuras laterais primárias pouco visíveis e pela espata curvada para trás.
A única coleta fértil foi realizada em julho, sendo necessário um estudo complementar de coletas e acompanhamento de material cultivado para registros de floração e frutificação e observação completa do fruto maduro. O material cultivado se desenvolve com as mesmas características daquele encontrado na natureza.

Até o momento, seguindo os critérios da lista vermelha das espécies ameaçadas, $A$. ameliae pode ser considerada em perigo critico (CR), por ocorrer numa área estimada menor que $100 \mathrm{~km}^{2}$ e somente de uma única localidade (IUCN 2001).

O epíteto específico homenageia a pesquisadora Amélia Olaio, amante das aráceas, pela sua contribuição no conhecimento e estudos com o referido grupo.

\section{Agradecimentos}

Os autores agradecem a Associação Pró Bocaina e o Instituto Brasileiro do Meio Ambiente (IBAMA) pelo esforço na conservação deste magnífico Parque, pelo apoio e autorizações para realização de duas expedições de coletas pelo Projeto Flora Fanerogâmica do Estado de São Paulo, durante as quais foram coletados materiais que permitiram a detecção das espécies aqui descritas. Agrademos também a Maria Cecília Tomasi, pela ilustração das espécies aqui descritas.

\section{REFERÊNCIAS BIBLIOGRÁFICAS}

Carroll, N. 2003. The Anthurium primer. Internet URL: http://www.aroid.org/TAP/ TAPstructure.html.

Coelho, M. A. N.; Waechter, J. L. \& Mayo, S. J. 2004. Taxonomia das espécies de Anthurium (Araceae) seção Urospadix subseção Flavescentiviridia. Tese de doutorado. Universidade Federal do Rio Grande do Sul, RS.

Croat, T. B. 1983. A revision of the genus Anthurium (Araceae) of Mexico and Central America. Part 1: Mexico and Central 
America. Annals of the Missouri Botanical Garden 70: 211-417.

Engler, A. 1878. Araceae. In Martius, C. F. P. von, Flora brasiliensis 3(2): 56-88, t. 11102.

Keating, R. C. 2002. Anatomy of the monocotyledons IX. Acoraceae and Araceae. 322 p. il. Clarendon Press. Oxford.

IBAMA. 2004. Unidades de Conservação. Parques Nacionais. Unidade: Parque Nacional da Serra da Bocaina. Internet URL: http://www.ibama.gov.br/siucweb/ mostraUc.php?seqUc=43.
IUCN. 2001. The IUCN red list of threatened species. Categories \& criteria (v. 3.1) Internet URL: $\underline{\text { http://www.redlist.org/info/ }}$ categories criteria2001.html.

Mayo, S. J.; Coelho, M. A. N.; Ramalho,F. C.; Sakuragui, C. M.; Soares, M. L. C. \& Barros, C. S. S. 1996. Checklist da família de Araceae no Brasil. Manuscrito. 92p.

Mayo, S. J.; Bogner, J. \& Boyce, P. C. 1997. The genera of Araceae. Continental Printing, Belgium. 370pp. il. 
